Check for updates

Cite this: Chem. Commun., 2020, 56,8679

Received 18th May 2020,

Accepted 18th June 2020

DOI: $10.1039 / \mathrm{d} 0 \mathrm{cc} 03539 \mathrm{~d}$

rsc.li/chemcomm

\section{Remarkable self-sorting selectivity in covalently linked homochiral and heterochiral pairs driven by $\mathrm{Pd}_{2} \mathrm{~L}_{4}$ helicate formation $\dagger$}

\author{
Daiji Ogata ${ }^{a b}$ and Junpei Yuasa (D) *ab
}

Imidazole-based ditopic ligands bearing two chiral alkyl groups $\left(\mathrm{L}^{R R}, \mathrm{~L}^{S S}\right.$, and $\left.\mathrm{L}^{R S}\right)$ were synthesized. The ligands formed $\mathrm{Pd}_{2} \mathrm{~L}_{4}$ helicates with palladium ions $\left(\mathrm{Pd}^{2+}\right)$. Self-sorting occurred between $\mathrm{L}^{R R}$ and $\mathrm{L}^{R S}$ to form $\left(\mathrm{Pd}^{2+}\right)_{2}\left(\mathrm{~L}^{R R}\right)_{4}$ and $\left(\mathrm{Pd}^{2+}\right)_{2}\left(\mathrm{~L}^{R S}\right)_{4}$ homoligand assemblies, whereas mixing of $\mathrm{L}^{R R}$ and $\mathrm{L}^{S S}$ with $\mathrm{Pd}^{2+}$ gave a near statistical mixture.

Chiral self-sorting is a specific molecular recognition process that distinguishes one enantiomer from a complex racemic mixture by self-recognition (narcissistic self-sorting) or selfdiscrimination (social self-sorting). ${ }^{1-8}$ This process is of fundamental importance for determining homochirality in biological systems and is informative for the development of efficient chiral separation methods and enantioselective catalysis. ${ }^{1}$ However, high-fidelity chiral self-sorting is challenging because enantiomers have equal sizes and shapes and only differ in their spatial orientations, although self-sorting may be the rule rather than the exception. ${ }^{9}$ This difficulty is compounded for chiral self-sorting between small molecules $(R$ and $S$ ) with a single chiral element in solution (Scheme 1a). In this case, covalent linking of chiral elements $(R+R$ and $S+S)$ to enhance the geometrical complementarity is a successful approach to facilitate high-fidelity chiral self-sorting (Scheme 1b). ${ }^{2 b, 5 c, 10}$ This strategy suggests that a new self-sorting process occurs with homochiral $(R R)$ and heterochiral $(R S)$ pairs. The pairs could either undergo self-recognition to give homochiral $(R R R R)$ and heterochiral (RSRS) assemblies (Scheme 1c, left) or preferentially recognize each other to yield a heteroassembly (RRRS) via self-discrimination (Scheme 1c, right). An important question that arises from this is which combination $(R R$ and $S S$

\footnotetext{
${ }^{a}$ Department of Applied Chemistry, Tokyo University of Science, 1-3 Kagurazaka, Shinjuku-ku, Tokyo 162-8601, Japan. E-mail: yuasaj@rs.tus.ac.jp

${ }^{b}$ Department of Chemistry, Graduate School of Science, Tokyo University of Science, 1-3 Kagurazaka, Shinjuku-ku, Tokyo 162-8601, Japan

$\dagger$ Electronic supplementary information (ESI) available: Experimental section, CD titration experiments for $\mathbf{L}^{S S}$, supporting scheme, relative energy levels of the isomers, ${ }^{1} \mathrm{H},{ }^{1} \mathrm{H}$ COSY NMR spectra, and variable temperature (VT) NMR spectra. See DOI: $10.1039 / \mathrm{d} 0 \mathrm{cc} 03539 \mathrm{~d}$
}

[Scheme 1b] or $R R$ and $R S$ [Scheme 1c]) is more effective for achieving self-sorting.

Herein, we report on the investigation of this key question about self-sorting of homochiral $(R R)$ and heterochiral $(R S)$ pairs. We selected an $\mathrm{M}_{2} \mathrm{~L}_{4}$ assembly as a platform to investigate the self-sorting, which was easy to design with $\mathrm{N}$-donor ditopic ligands (L) with a square planar coordination metal such as $\mathrm{Pd}^{2+}(\mathrm{M}) .^{8,11,12}$ Notably, pyridine-based ditopic N-donor ligands are predominant in coordination assemblies. We have developed imidazole-based $\mathrm{N}$-donor ditopic ligands for a coordination assembly system we term "metal-ion clipping". ${ }^{13}$ Through our studies on metal-ion clipping, we have found that the benefit of the imidazole-based ditopic ligands is the synthetic accessibility of the imidazole nitrogen, which allows for easy introduction of multiple chiral centers into ditopic ligands to impart helical sense in the resulting self-assembly. In the

(a)

(b)

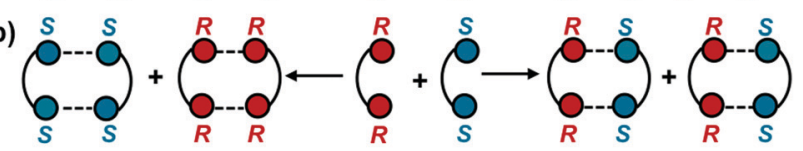

(c)

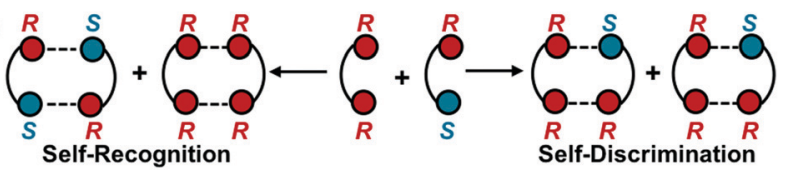

(d)

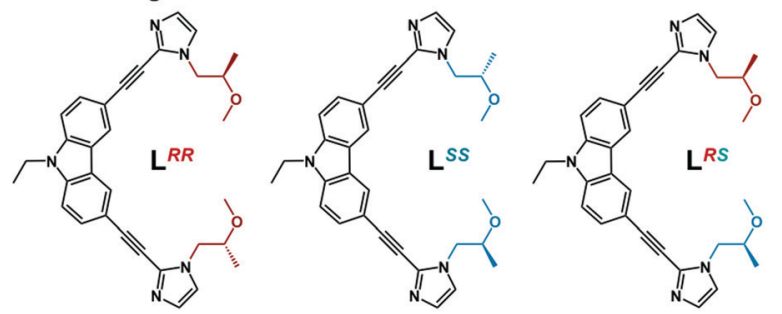

Scheme 1 Schematic representation of self-recognition and selfdiscrimination between (a) enantiomer pairs ( $R$ and $S)$, (b) covalently linked homochiral pairs (RR and SS), and (c) homochiral and heterochiral pairs (RR and $R S)$. (d) The structures of $\mathrm{L}^{R R}, \mathrm{~L}^{S S}$, and $\mathrm{L}^{R S}$. 
present work, we synthesize imidazole-based ditopic ligands bearing two chiral alkyl groups (Scheme $1 \mathrm{~d}, \mathbf{L}^{\boldsymbol{R} \boldsymbol{R}}, \mathbf{L}^{\boldsymbol{S S}}$, and $\mathbf{L}^{\boldsymbol{R} \boldsymbol{S}}$ ), which formed a $\mathrm{Pd}_{2} \mathrm{~L}_{4}$ helicate assembly with $\mathrm{Pd}^{2+}$. Our study revealed a remarkable self-recognition selectivity between $\mathbf{L}^{\boldsymbol{R} \boldsymbol{R}}$ and $\mathbf{L}^{\boldsymbol{R S}}$ through the process of $\mathrm{Pd}_{2} \mathrm{~L}_{4}$ helicate formation. Conversely, no appreciable self-sorting took place between $\mathbf{L}^{\boldsymbol{R} \boldsymbol{R}}$ and $\mathbf{L}^{\boldsymbol{S S}}$. The present findings will be informative for studies of chiral self-sorting and its applications.

The homochiral ditopic ligands $\left(\mathbf{L}^{\boldsymbol{R} \boldsymbol{R}}\right.$ and $\left.\mathbf{L}^{\boldsymbol{S S}}\right)$ themselves exhibited no circular dichroism (CD) signal but induced intense CD signals were observed on the addition of 0-0.5 equiv. of $\left[\mathrm{Pd}\left(\mathrm{CH}_{3} \mathrm{CN}\right)_{4}\right]\left(\mathrm{BF}_{4}\right)_{2}$ (Fig. 1a; see ESI, $\dagger$ Fig. S1).$^{13-15}$ The CD intensity change at $292 \mathrm{~nm}\left(\Delta \varepsilon_{292}\right)$ reached saturation at $\left[\mathrm{Pd}^{2+}\right] /$ $\left[\mathbf{L}^{R R}\right]_{0}=0.5$ (Fig. 1b) in the titration plot, indicating that a remarkable $\mathrm{CD}$ intensity enhancement (Fig. 1a) was caused by the formation of a $\operatorname{Pd}_{2} \mathrm{~L}_{4}$ between $\mathrm{Pd}^{2+}$ and $\mathbf{L}^{\boldsymbol{R} \boldsymbol{R}}$ (or $\mathbf{L}^{\boldsymbol{S S}}$ ) [here, the charge on the $\operatorname{Pd}_{2} \mathrm{~L}_{4}$ assembly is $\left.4+\right]$. Next, we measured the mass of $\mathbf{L}^{\boldsymbol{S S}}$ in acetonitrile containing 0.5 equiv. of $\left[\mathrm{Pd}\left(\mathrm{CH}_{3} \mathrm{CN}\right)_{4}\right]\left(\mathrm{BF}_{4}\right)_{2}$ using positive-mode electrospray ionization (Fig. 1e). Intense peaks corresponding to the $\operatorname{Pd}_{2} \mathrm{~L}_{4}$ assembly were successfully detected $\left(\left[(\mathrm{Pd})_{2}\left(\mathbf{L}^{S \boldsymbol{S}}\right)_{4}+n\left(\mathrm{BF}_{4}\right)\right]^{(4-n)+}\right)$, which was direct evidence of the $\mathrm{Pd}_{2} \mathrm{~L}_{4}$ assembly formation. Conversely, single crystals of the $\mathrm{Pd}_{2} \mathrm{~L}_{4}$ assemblies could not be grown, probably because of the conformational flexibility of the chiral alkyl groups attached on the two imidazole side arms of the ditopic ligands. To reduce the complexity, we replaced the chiral alkyl groups with methyl groups $\left(\mathbf{L}^{\boldsymbol{R} \boldsymbol{R}} \rightarrow \mathbf{L}^{\prime}\right)$ and used $\mathbf{L}^{\prime}$ as an isomorph suitable for


(d)
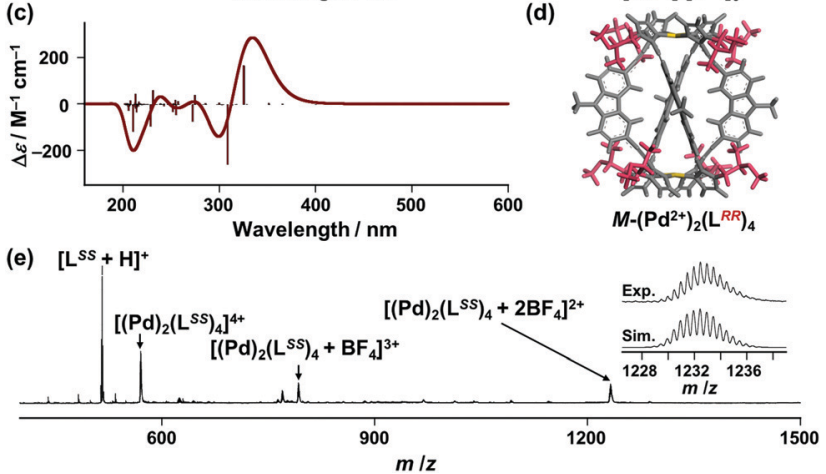

Fig. 1 (a) CD spectral changes observed during the titration of $\mathbf{L}^{R R}(2.3 \times$ $\left.10^{-5} \mathrm{M}\right)$ with $\mathrm{Pd}^{2+}\left(0-6.9 \times 10^{-5} \mathrm{M}\right)$ in acetonitrile. (b) Plot of $\Delta \varepsilon$ at $292 \mathrm{~nm}$ versus $\left[\mathrm{Pd}^{2+}\right] /\left[\mathrm{L}^{R R}\right]_{0}$. (c) Theoretical CD spectrum [time dependent-DFT/ CAM-B3LYP-6-31G(d)/LANL2DZ (Pd)] and (d) the optimized structure [DFT/B3LYP-6-31G(d)/LANL2DZ (Pd)] of $M-\left(\mathrm{Pd}^{2+}\right)_{2}\left(\mathrm{~L}^{R R}\right)_{4}$, where the ethyl groups at the carbazole spacers were replaced by methyl groups to reduce the calculation complexity. $\Delta \varepsilon[(\mathrm{a}-\mathrm{c})]$ was calculated using the concentration of $\mathrm{L}^{R R}$. (e) Positive-mode electrospray ionization MS of a solution of $\mathrm{L}^{S S}\left(2.0 \times 10^{-3} \mathrm{M}\right)$ in acetonitrile in the presence of $\left[\mathrm{Pd}\left(\mathrm{CH}_{3} \mathrm{CN}\right)_{4}\right]\left(\mathrm{BF}_{4}\right)_{2}$ $\left(1.0 \times 10^{-3} \mathrm{M}\right)$. The inset shows isotopically resolved signals at $\mathrm{m} / \mathrm{z}=$ 1232.4 and the calculated isotopic distributions for $\left[(\mathrm{Pd})_{2}\left(\mathrm{~L}^{\mathrm{SS}}\right)_{4}+2 \mathrm{BF}_{4}\right]^{2+}$. growing single crystals. These modifications enabled us to obtain single crystals through a slow vapor diffusion of diethyl ether into the acetonitrile solution containing $\left(\mathrm{Pd}^{2+}\right)_{2}\left(\mathbf{L}^{\prime}\right)_{4}$. The X-ray crystal structure analysis revealed that $\mathbf{L}^{\prime}$ formed a $\operatorname{Pd}_{2} \mathrm{~L}_{4}$ assembly with a helical structure (ESI, $\dagger$ Fig. S2). In light of these results, the structure of $\left(\mathrm{Pd}^{2+}\right)_{2}\left(\mathbf{L}^{R R}\right)_{4}$ was modeled with reference to the X-ray crystal structure of $\left(\mathrm{Pd}^{2+}\right)_{2}\left(\mathbf{L}^{\prime}\right)_{4}$ and optimized with density functional theory (DFT) [B3LYP-6-31G(d)/LANL2DZ (Pd)] (Fig. 1d). Then, we performed time-dependent DFT calculations on the optimized structure of $\left(\mathrm{Pd}^{2+}\right)_{2}\left(\mathbf{L}^{R R}\right)_{4}$ with $M$ helicity. In this case, the theoretical CD spectrum (Fig. 1c) essentially agreed with the experimental one (Fig. 1a). This finding allowed us to assign $M$ as the favored helicity for $\left(\mathrm{Pd}^{2+}\right)_{2}\left(\mathbf{L}^{R R}\right)_{4}$ (Table 1, entry 1). The DFT calculations indicated that $M-\left(\mathrm{Pd}^{2+}\right)_{2}\left(\mathbf{L}^{\boldsymbol{R} R}\right)_{4}$ was $14.06 \mathrm{kcal} \mathrm{mol}^{-1}$ lower in energy than $P-\left(\mathrm{Pd}^{2+}\right)_{2}\left(\mathbf{L}^{\boldsymbol{R} R}\right)_{4}$. This energy difference is probably because of the difference in steric hindrance between the $P$ - and $M$-isomers with regard to the helix backbone formed by the carbazole spacers and the chiral alkyl groups (ESI, $\dagger$ Fig. S4).

Next, we examined the $\operatorname{Pd}_{2} \mathrm{~L}_{4}$ helicate using NMR spectroscopy (Fig. 2a-c and ESI, $\dagger$ Fig. S5 and S6). Upon the addition of 0.5 equiv. of $\left[\mathrm{Pd}\left(\mathrm{CH}_{3} \mathrm{CN}\right)_{4}\right]\left(\mathrm{BF}_{4}\right)_{2}$ to $\mathbf{L}^{R \boldsymbol{R}}$ in $\mathrm{CD}_{3} \mathrm{CN}$, upfield $(\mathrm{A}, \mathrm{B}, \mathrm{D}$, and $\mathrm{E}$ ) and downfield (C and $\mathrm{F}$ ) shifts were observed compared with the free $\mathbf{L}^{\boldsymbol{R} \boldsymbol{R}}$ (Fig. 2a and b). However, the total number of peaks remained the same as for the free ligand (Fig. 2a and b), indicating that the $\mathbf{L}^{\boldsymbol{R} R}$ ligands bound to $\mathrm{Pd}^{2+}$ ions adopted the same coordination environment and retained the original ligand symmetry $\left(C_{2}\right)$. This finding was consistent with the symmetrical $\left(\mathrm{Pd}^{2+}\right)_{2}\left(\mathbf{L}^{\boldsymbol{R} \boldsymbol{R}}\right)_{4}$ helicate (Fig. 1d). By contrast, when the heterochiral ditopic ligand $\left(\mathbf{L}^{\boldsymbol{R S}}\right)$ was used instead of $\mathbf{L}^{\boldsymbol{R} \boldsymbol{R}}$, each signal (except

Table 1 Summary of the $\mathrm{Pd}_{2} \mathrm{~L}_{4}$ assembly formation (ESI, Fig. S3)

\begin{tabular}{|c|c|c|}
\hline No. & Ligands & Resulting assembly \\
\hline 1 & $\mathrm{~L}^{R R}$ & $M-\left(\mathrm{Pd}^{2+}\right)_{2}\left(\mathbf{L}^{R R}\right)_{4}$ \\
\hline 2 & $\mathrm{~L}^{R S}$ & $\begin{array}{l}P-(R R R S / S S S R)-\left(\mathrm{Pd}^{2+}\right)_{2}\left(\mathbf{L}^{R S}\right)_{4} \\
M-(R R R S / S S S R)-\left(\mathrm{Pd}^{2+}\right)_{2}\left(\mathbf{L}^{R S}\right)_{4}\end{array}$ \\
\hline 3 & $\mathbf{L}^{R R}+\mathbf{L}^{S S}$ & $\begin{array}{l}P-\left(\mathrm{Pd}^{2+}\right)_{2}\left(\mathbf{L}^{S S}\right)_{4} \\
M-\left(\mathrm{Pd}^{2+}\right)_{2}\left(\mathbf{L}^{R R}\right)_{4} \\
\left.P-\left(\mathrm{Pd}^{2+}\right)_{2}\left(\mathbf{L}^{R R}\right)_{(\mathbf{L}} S\right)_{3} \\
M-\left(\mathrm{Pd}^{2+}\right)_{2}\left(\mathbf{L}^{R R}\right)_{3}\left(\mathbf{L}^{S S}\right) \\
P-\left(\mathrm{Pd}^{2+}\right)_{2}\left(\mathbf{L}^{R R}\right)_{3}\left(\mathbf{L}^{S S}\right) \\
M-\left(\mathrm{Pd}^{2+}\right)_{2}\left(\mathbf{L}^{R R}\right)\left(\mathbf{L}^{S S}\right)_{3} \\
P-(R S S R / R S S R)-\left(\mathrm{Pd}^{2+}\right)_{2}\left(\mathbf{L}^{R R}\right)_{2}\left(\mathbf{L}^{S S}\right)_{2} \\
M-(R S S R / R S S R)-\left(\mathrm{Pd}^{2+}\right)_{2}\left(\mathbf{L}^{R R}\right)_{2}\left(\mathbf{L}^{S S}\right)_{2} \\
P-(R S R S / R S R S)-\left(\mathrm{Pd}^{2+}\right)_{2}\left(\mathbf{L}^{R R}\right)_{2}\left(\mathbf{L}^{S S}\right)_{2} \\
M-(R S R S / R S R S)-\left(\mathrm{Pd}^{2+}\right)_{2}\left(\mathbf{L}^{R R}\right)_{2}\left(\mathbf{L}^{S S}\right)_{2}\end{array}$ \\
\hline 4 & $\mathbf{L}^{R R}+\mathbf{L}^{R S}$ & $\begin{array}{l}M-\left(\mathrm{Pd}^{2+}\right)_{2}\left(\mathbf{L}^{R R}\right)_{4} \\
P-(R R R S / S S S R)-\left(\mathrm{Pd}^{2+}\right)_{2}\left(\mathbf{L}^{R S}\right)_{4} \\
M-(R R R S / S S S R)-\left(\mathrm{Pd}^{2+}\right)_{2}\left(\mathbf{L}^{R S}\right)_{4}\end{array}$ \\
\hline 5 & $\mathbf{L}^{R R}+\mathbf{L}^{S S}+\mathbf{L}^{R S}$ & $\begin{array}{l}P-\left(\mathrm{Pd}^{2+}\right)_{2}\left(\mathbf{L}^{S S}\right)_{4} \\
M-\left(\mathrm{Pd}^{2+}\right)_{2}\left(\mathbf{L}^{R R}\right)_{4} \\
\left.P-\left(\mathrm{Pd}^{2+}\right)_{2}\left(\mathbf{L}^{R R}\right)_{(} \mathbf{L}^{S S}\right)_{3} \\
M-\left(\mathrm{Pd}^{2+}\right)_{2}\left(\mathbf{L}^{R R}\right)_{3}\left(\mathbf{L}^{S S}\right) \\
P-\left(\mathrm{Pd}^{2+}\right)_{2}\left(\mathbf{L}^{R R}\right)_{3}\left(\mathbf{L}^{S S}\right) \\
M-\left(\mathrm{Pd}^{2+}\right)_{2}\left(\mathbf{L}^{R R}\right)\left(\mathbf{L}^{S S}\right)_{3} \\
P-(R S S R / R S S R)-\left(\mathrm{Pd}^{2+}\right)_{2}\left(\mathbf{L}^{R R}\right)_{2}\left(\mathbf{L}^{S S}\right)_{2} \\
M-(R S S R / R S S R)-\left(\mathrm{Pd}^{2+}\right)_{2}\left(\mathbf{L}^{R R}\right)_{2}\left(\mathbf{L}^{S S}\right)_{2} \\
P-(R S R S / R S R S)-\left(\mathrm{Pd}^{2+}\right)_{2}\left(\mathbf{L}^{R R}\right)_{2}\left(\mathbf{L}^{S S}\right)_{2} \\
M-(R S R S / R S R S)-\left(\mathrm{Pd}^{2+}\right)_{2}\left(\mathbf{L}^{R R}\right)_{2}\left(\mathbf{L}^{S S}\right)_{2} \\
P-(R R R S / S S S R)-\left(\mathrm{Pd}^{2+}\right)_{2}\left(\mathbf{L}^{R S}\right)_{4} \\
M-(R R R S / S S S R)-\left(\mathrm{Pd}^{2+}\right)_{2}\left(\mathbf{L}^{R S}\right)_{4}\end{array}$ \\
\hline
\end{tabular}



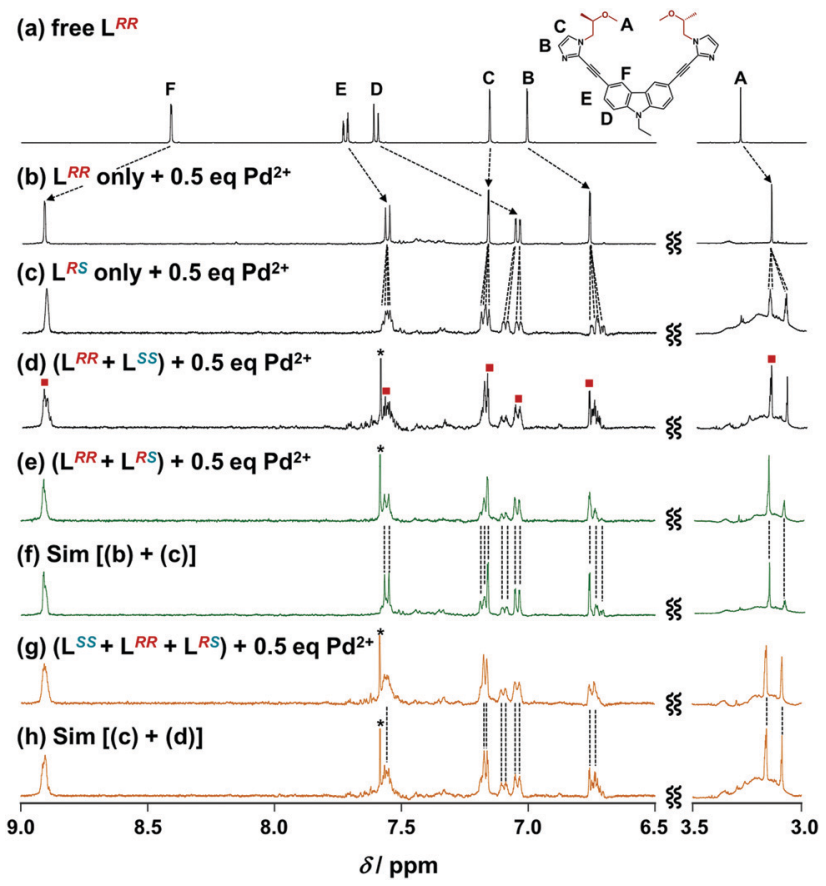

Fig. 2 (a) ${ }^{1} \mathrm{H}$ NMR spectrum of free $\mathrm{L}^{R R}$ in $\mathrm{CD}_{3} \mathrm{CN}$. ${ }^{1} \mathrm{H}$ NMR spectra of (b) $\mathrm{L}^{R R}$ $\left(4.0 \times 10^{-3} \mathrm{M}\right)$, (c) $\mathrm{L}^{R S}\left(4.0 \times 10^{-3} \mathrm{M}\right)$, (d) mixture of $\mathrm{L}^{S S}\left(2.0 \times 10^{-3} \mathrm{M}\right)$ and $\mathrm{L}^{R R}$ $\left(2.0 \times 10^{-3} \mathrm{M}\right)$, (e) mixture of $\mathrm{L}^{R R}\left(2.0 \times 10^{-3} \mathrm{M}\right)$ and $\mathrm{L}^{R S}\left(2.0 \times 10^{-3} \mathrm{M}\right)$, and (g) mixture of $\mathrm{L}^{S S}\left(1.3 \times 10^{-3} \mathrm{M}\right), \mathrm{L}^{R R}\left(1.3 \times 10^{-3} \mathrm{M}\right)$, and $\mathrm{L}^{R S}\left(1.3 \times 10^{-3} \mathrm{M}\right)$ in $\mathrm{CD}_{3} \mathrm{CN}$ containing $2.0 \times 10^{-3} \mathrm{M}$ of $\mathrm{Pd}^{2+}$ at $298 \mathrm{~K}$. The chloroform peak is marked with an asterisk. The peaks marked with red squares correspond to $\left(\mathrm{Pd}^{2+}\right)_{2}\left(\mathrm{~L}^{R R}\right)_{4}$ and $\left(\mathrm{Pd}^{2+}\right)_{2}\left(\mathrm{~L}^{S S}\right)_{4}$. (f and $\left.\mathrm{h}\right)$ Simulated ${ }^{1} \mathrm{H}$ NMR spectra obtained from the sum of two experimental ${ }^{1} \mathrm{H}$ NMR spectra.

for F) was split into four (Fig. 2b and c). This splitting could be attributed to a change in the ligand symmetry through the $\operatorname{Pd}_{2} \mathrm{~L}_{4}$ assembly. Statistically, there are four coordination isomers present (excluding the enantiomers) depending on the coordination pattern of $\mathbf{L}^{\boldsymbol{R S}}$ in the $\operatorname{Pd}_{2} \mathrm{~L}_{4}$ assembly (Fig. 3), where their forms were defined based on the chiral sequences of the top and bottom squares formed by the chiral groups (e.g., (RRRS)/(SSSR), see details in the ESI $\dagger$ ). DFT calculations suggested that the four possible isomers had almost the same energy $\left(\Delta E<1.6 \mathrm{kcal} \mathrm{mol}^{-1}\right.$, Fig. 3). Among the isomers, the statistically most probable species [ $R R R S /$ $\left.S S S R)-\left(\mathrm{Pd}^{2+}\right)_{2}\left(\mathbf{L}^{R S}\right)_{4}\right]$ has the four imidazole rings located in different coordination environments (Fig. 3), which could explain the observed splitting pattern in the NMR spectrum of the $\mathrm{Pd}^{2+} / \mathbf{L}^{\text {RS }}$ system (Fig. 2c). By contrast, splitting into two at most could be expected for the NMR signals of the other $\left(\mathrm{Pd}^{2+}\right)_{2}\left(\mathbf{L}^{\boldsymbol{R S}}\right)_{4}$ isomers (Fig. 3), which means that these species are inconsistent with the observed NMR splitting pattern (Fig. 2c). In the variabletemperature NMR experiments (ESI, $\dagger$ Fig. S7), the relative integration ratio for each split signal remained unchanged between 295 and $346 \mathrm{~K}$. These results indicate that $\mathbf{L}^{\boldsymbol{R S}}$ predominantly forms the statistically most probable species $\left[(R R R S / S R R R)-\left(\mathrm{Pd}^{2+}\right)_{2}\left(\mathbf{L}^{R S}\right)_{4}\right]$ (Table 1 , entry 2). ${ }^{16}$

When $\mathbf{L}^{\boldsymbol{R} \boldsymbol{R}}$ and $\mathbf{L}^{\boldsymbol{S S}}$ were mixed in a 1:1 ratio in the presence of 0.5 equiv. of $\mathrm{Pd}^{2+}$ (relative to the total ligand concentration), a complicated NMR spectrum was obtained (Fig. 2d). The spectrum contained several peaks other than those assigned

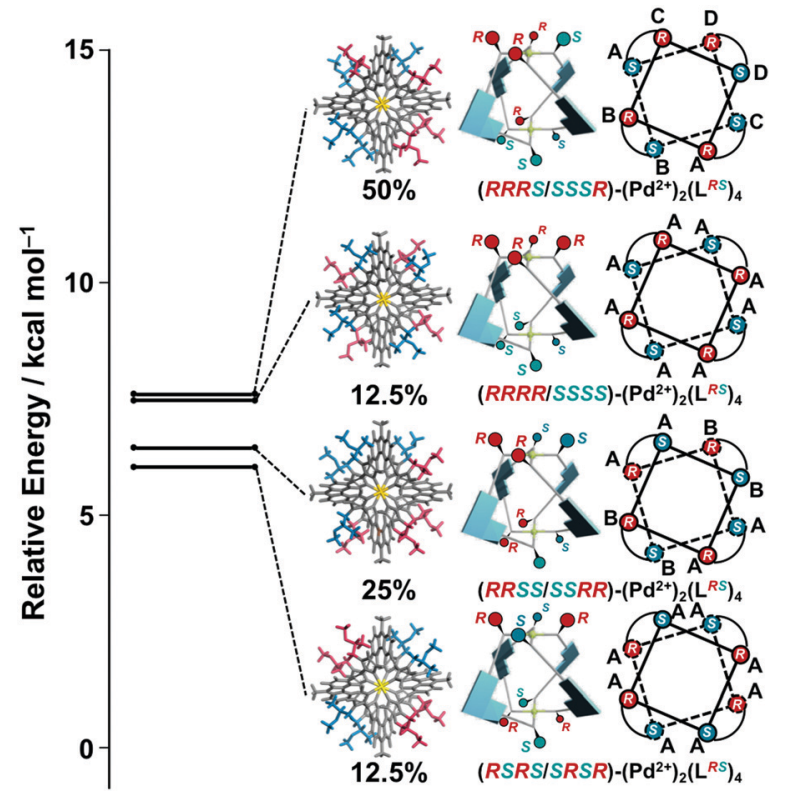

Fig. 3 Left: statistical probability of $\left(\mathrm{Pd}^{2+}\right)_{2}\left(\mathrm{~L}^{R S}\right)_{4}$, where the enantiomers $(P$ - or $M$-helix) are not distinguished. Relative energy levels of the optimized structures of [DFT/B3LYP-6-31G(d)/LANL2DZ (Pd)] of $\left(\mathrm{Pd}^{2+}\right)_{2}\left(\mathrm{~L}^{R S}\right)_{4}$. The chiral alkyl groups ( $R$ and $S$ ) attached on the two imidazole side arms are colored in red and blue, respectively. The ethyl groups at the carbazole spacers were replaced by methyl groups to reduce the calculation complexity. Here, the energy of $\mathrm{M}-\left(\mathrm{Pd}^{2+}\right)_{2}\left(\mathrm{~L}^{R R}\right)_{4}$ (the most stable species) is referenced to zero. Right: schematic representations of the four isomers of $\left(\mathrm{Pd}^{2+}\right)_{2}\left(\mathrm{~L}^{R S}\right)_{4}$. The imidazole rings in different coordination environments are distinguished by the labels A-D.

to the homochiral assemblies, $\left(\mathrm{Pd}^{2+}\right)_{2}\left(\mathbf{L}^{\boldsymbol{R R}}\right)_{4}$ and $\left(\mathrm{Pd}^{2+}\right)_{2}\left(\mathbf{L}^{\boldsymbol{S S}}\right)_{4}$ (red squares, Fig. 2d), indicating a near statistical isomerization (Table 1, entry 3). Notably, the variable-temperature NMR experiments (ESI, $\dagger$ Fig. S7) revealed that the relative integration ratio between the split peaks changed with an increase in the temperature from 296 to $348 \mathrm{~K}$. This suggested that the complicated NMR signals (Fig. 2d) arose from the statistical mixture. There are 12 possible isomers, including enantiomers, and DFT calculations indicated that their energies were spread over $14.06 \mathrm{kcal} \mathrm{mol}^{-1}$ and some of them were close in energy (ESI, $\dagger$ Fig. S8). In contrast to the complexity of the $\mathbf{L}^{\boldsymbol{R} R} / \mathbf{L}^{\boldsymbol{S S}}$ system (enantiomeric combination of homochiral pairs) in the NMR spectrum (Fig. 2d), mixing $\mathbf{L}^{\boldsymbol{R} R}$ (homochiral pair) with $\mathbf{L}^{\boldsymbol{R} S}$ (heterochiral pair) in the presence of 0.5 equiv. of $\mathrm{Pd}^{2+}$ resulted in a rather simple NMR spectrum (Fig. 2e). The resulting NMR spectrum (Fig. 2e) could be reproduced as a calculated spectrum (Fig. 2f) from the sum of the two experimental NMR spectra (Fig. 2b and c) corresponding to the homoligand assemblies, $\left(\mathrm{Pd}^{2+}\right)_{2}\left(\mathbf{L}^{R R}\right)_{4}$ and $\left(\mathrm{Pd}^{2+}\right)_{2}\left(\mathbf{L}^{R S}\right)_{4}$. The good agreement between the two NMR spectra (Fig. 2e and f) clearly indicated that $\mathbf{L}^{\boldsymbol{R} R}$ and $\mathbf{L}^{\boldsymbol{R} S}$ individually assembled into the homoligand assemblies $\left(\mathrm{Pd}^{2+}\right)_{2}\left(\mathbf{L}^{R R}\right)_{4}$ and $\left(\mathrm{Pd}^{2+}\right)_{2}\left(\mathbf{L}^{\boldsymbol{R S}}\right)_{4}$ by selfrecognition (Table 1 , entry 4 ). This was a surprising result given that the remarkable self-sorting selectivity worked between the covalently linked homochiral pair $\left(\mathbf{L}^{\boldsymbol{R} R}\right)$ and heterochiral pair $\left(\mathbf{L}^{\boldsymbol{R S}}\right)$ through the $\mathrm{Pd}_{2} \mathrm{~L}_{4}$ assembly, whereas a total of 22 possible 
isomers (excluding the enantiomers) were envisioned between $\mathbf{L}^{\boldsymbol{R} \boldsymbol{R}}$ and $\mathbf{L}^{\boldsymbol{R} \boldsymbol{S}}$ (ESI, $\dagger$ Fig. S9). Among the possible isomers, DFT calculations indicated that $M-\left(\mathrm{Pd}^{2+}\right)_{2}\left(\mathbf{L}^{R R}\right)_{4}$ (homoligand assembly) was the most thermodynamically stable species (ESI, $\dagger$ Fig. S9). However, $\left(\mathrm{Pd}^{2+}\right)_{2}\left(\mathbf{L}^{\boldsymbol{R} R}\right)_{3}\left(\mathbf{L}^{\boldsymbol{R S}}\right)$ (heteroligand assembly) was the most statistically probable species (ESI, $\uparrow$ Fig. S9). If an effective thermodynamic bias exists in this system, $\mathbf{L}^{\boldsymbol{R} \boldsymbol{R}}$ would mostly form the homoligand assembly $\left(M-\left(\mathrm{Pd}^{2+}\right)_{2}\left(\mathbf{L}^{\boldsymbol{R} R}\right)_{4}\right)$. As a result, $\mathbf{L}^{\boldsymbol{R S}}$ has no opportunity to assemble with $\mathbf{L}^{\boldsymbol{R} \boldsymbol{R}}$ to yield heteroligand assemblies such as $\left(\mathrm{Pd}^{2+}\right)_{2}\left(\mathbf{L}^{\boldsymbol{R}}\right)_{3}\left(\mathbf{L}^{\boldsymbol{R S}}\right)$ because of the lack of a ligand partner $\left(\mathbf{L}^{\boldsymbol{R S}}\right)$. Therefore, the homoligand assembly $\left(\mathrm{Pd}^{2+}\right)_{2}\left(\mathbf{L}^{R S}\right)_{4}$ is predominant. This may be the most probable explanation of the strong self-sorting behavior observed between $\mathbf{L}^{\boldsymbol{R} R}$ and $\mathbf{L}^{\boldsymbol{R S}}$ in the $\operatorname{Pd}_{2} \mathrm{~L}_{4}$ assembly process.

Finally, the self-sorting effect in a ternary system $\left(\mathbf{L}^{R R}+\mathbf{L}^{S S}+\right.$ $\left.\mathbf{L}^{R S}\right)$ was investigated. The addition of 0.5 equiv. of $\mathrm{Pd}^{2+}$ to a mixture of $\mathbf{L}^{\boldsymbol{R} \boldsymbol{R}}, \mathbf{L}^{\boldsymbol{S S}}$, and $\mathbf{L}^{\boldsymbol{R S}}$ resulted in a rather complicated NMR spectrum (Fig. 2g), which could be reproduced in a calculated NMR spectrum (Fig. 2h) derived from the sum of the two experimentally obtained NMR spectra for the $\mathbf{L}^{\boldsymbol{R}} / \mathrm{Pd}^{2+}$ (Fig. 2c) and $\left(\mathbf{L}^{\boldsymbol{R} \boldsymbol{R}}+\mathbf{L}^{\boldsymbol{S S}}\right) / \mathrm{Pd}^{2+}$ systems (Fig. 2d). A strong self-sorting selectivity was preserved even in the ternary system $\left(\mathbf{L}^{\boldsymbol{R} \boldsymbol{R}}+\mathbf{L}^{\boldsymbol{S S}}+\right.$ $\mathbf{L}^{\boldsymbol{R S}}$ ), in which the enantiomeric combination of homochiral ditopic ligands $\left(\mathbf{L}^{\boldsymbol{R} \boldsymbol{R}}\right.$ and $\mathbf{L}^{\boldsymbol{S S}}$ ) provided an almost statistical mixture. By contrast, the heterochiral ditopic ligand $\left(\mathbf{L}^{\boldsymbol{R S}}\right)$ narcissistically self-assembled into $\left(\mathrm{Pd}^{2+}\right)_{2}\left(\mathbf{L}^{R S}\right)_{4}$ (Table 1 , entry 5).

In conclusion, we successfully demonstrated a remarkable selfsorting selectivity in covalently linked homochiral and heterochiral pairs ( $\mathbf{L}^{\boldsymbol{R} R}$ and $\mathbf{L}^{\boldsymbol{R} S}$ ) through a $\operatorname{Pd}_{2} \mathrm{~L}_{4}$ assembly process to produce self-recognition products $\left[\left(\mathrm{Pd}^{2+}\right)_{2}\left(\mathbf{L}^{\boldsymbol{R} R}\right)_{4}\right.$ and $\left.\left(\mathrm{Pd}^{2+}\right)_{2}\left(\mathbf{L}^{\boldsymbol{R S}}\right)_{4}\right]$. By contrast, the enantiomeric combination of homochiral pairs $\left(\mathbf{L}^{R R}\right.$ and $\left.\mathbf{L}^{S S}\right)$ with $\mathrm{Pd}^{2+}$ produces a near statistical mixture. The present results are of interest for identifying potential new chiral self-sorting strategies.

This work was partly supported by JSPS KAKENHI Scientific Research on Innovative Areas "Coordination Asymmetry" (Grant Numbers 19H02693, 19K22207, and 19H04596), and a Grant-inAid from the Asahi Glass Foundation. We thank Gabrielle David, PhD, from Edanz Group (www.edanzediting.com/ac) for editing a draft of this manuscript.

\section{Conflicts of interest}

There are no conflicts to declare.

\section{Notes and references}

1 (a) M. Liu, L. Zhang and T. Wang, Chem. Rev., 2015, 115, 7304; (b) H. Jedrzejewska and A. Szumna, Chem. Rev., 2017, 117, 4863; (c) R. L. Greenaway, V. Santolini, A. Pulido, M. A. Little, B. M. Alston, M. E. Briggs, G. M. Day, A. I. Cooper and K. E. Jelfs, Angew. Chem., Int. Ed., 2019, 58, 16275; (d) L.-J. Chen, H.-B. Yang and M. Shionoya, Chem. Soc. Rev., 2017, 46, 2555; (e) M. M. Safont-Sempere, G. Fernández and F. Würthner, Chem. Rev., 2011, 111, 5784.

2 (a) J. Zhong, L. Zhang, D. P. August, G. F. S. Whitehead and D. A. Leigh, J. Am. Chem. Soc., 2019, 141, 14249; (b) T. Tateishi, T. Kojima and S. Hiraoka, Commun. Chem., 2018, 1, 20; (c) S. Kai,
T. Kojima, F. L. Thorp-Greenwood, M. J. Hardie and S. Hiraoka, Chem. Sci., 2018, 9, 4104; (d) E. Chinnaraja, R. Arunachalam, E. Suresh, S. K. Sen, R. Natarajan and P. S. Subramanian, Inorg. Chem., 2019, 58, 4465; $(e)$ V. E. Pritchard, D. Rota Martir, S. Oldknow, S. Kai, S. Hiraoka, N. J. Cookson, E. Zysman-Colman and M. J. Hardie, Chem. -Eur. J., 2017, 23, 6290; $(f)$ S. A. Boer and D. R. Turner, Chem. Commun., 2015, 51, 17375; (g) O. Gidron, M. Jirásek, N. Trapp, M. O. Ebert, X. Zhang and F. Diederich, J. Am. Chem. Soc., 2015, 137, 12502; (h) M. Horie, N. Ousaka, D. Taura and E. Yashima, Chem. Sci., 2015, 6, 714 .

3 C. Maeda, T. Kamada, N. Aratani and A. Osuka, Coord. Chem. Rev., 2007, 251, 2743.

4 (a) C. Kaes, M. W. Hosseini, C. E. F. Rockard, B. W. Skelton and A. H. White, Angew. Chem., Int. Ed., 1998, 37, 920; (b) M. A. Masood, E. J. Enemark and T. D. P. Stack, Angew. Chem., Int. Ed., 1998, 37, 928; (c) S. G. Telfer, T. Sato, R. Kuroda, J. Lefebvre and D. B. Leznoff, Inorg. Chem., 2004, 43, 421; (d) T. W. Kim, M. S. Lahb and J.-I. Hong, Chem. Commun., 2001, 743; (e) J. M. Rowland, M. M. Olmstead and P. K. Mascharak, Inorg. Chem., 2002, 41, 1545.

5 (a) D. Beaudoin, F. Rominger and M. Mastalerz, Angew. Chem., Int. Ed., 2017, 56, 1244; (b) L. Y. Yao, T. K. M. Lee and V. W. W. Yam, J. Am. Chem. Soc., 2016, 138, 7260; (c) L.-L. Yan, C.-H. Tan, G.-L. Zhang, L.-P. Zhou, J.-C. Bunzli and Q.-F. Sun, J. Am. Chem. Soc., 2015, 137, 8550; (d) C. G. Claessens and T. Torres, J. Am. Chem. Soc., 2002, 124, 14522.

6 For chiral-self-sorting upon coordination assembly, see: $(a)$ L. Volbach, N. Struch, F. Bohle, F. Topić, G. Schnakenburg, A. Schneider, K. Rissanen, S. Grimme and A. Lützen, Chem. - Eur. J., 2020, 26, 3335; (b) J. Anhäuser, R. Puttreddy, L. Glanz, A. Schneider, M. Engeser, K. Rissanen and A. Lützen, Chem. - Eur. J., 2019, 25, 12294; (c) N. Struch, C. Frömbgen, G. Schnakenburg and A. Lützen, Eur. J. Org. Chem., 2017, 4984; (d) A. Jarzebski, C. Tenten, C. Bannwarth, G. Schnakenburg, S. Grimme and A. Lützen, Chem. - Eur. J., 2017, 23, 12380; (e) C. Guetz, R. Hovorka, N. Struch, J. Bunzen, G. MeyerEppler, Z.-W. Qu, S. Grimme, F. Topic, K. Rissanen, M. Cetina, M. Engeser and A. Lützen, J. Am. Chem. Soc., 2014, 136, 11830; $(f)$ G. Meyer-Eppler, F. Topić, G. Schnakenburg, K. Rissanen and A. Lützen, Eur. J. Inorg. Chem., 2014, 2495; $(g)$ C. Guetz, R. Hovorka, C. Klein, Q.-Q. Jiang, C. Bannwarth, M. Engeser, C. Schmuck, W. Assenmacher, W. Mader, F. Topic, K. Rissanen, S. Grimme and A. Lützen, Angew. Chem., Int. Ed., 2014, 53, 1693.

7 (a) K. Nonomura and J. Yuasa, Inorg. Chem., 2019, 58, 6474; (b) T. Y. Bing, T. Kawai and J. Yuasa, J. Am. Chem. Soc., 2018, 140, 3683. 8 (a) T. R. Schulte, J. J. Holstein and G. H. Clever, Angew. Chem., Int. Ed., 2019, 58, 5562; (b) J. Anhäuser, R. Puttreddy, Y. Lorenz, A. Schneider, M. Engeser, K. Rissanen and A. Lützen, Org. Chem. Front., 2019, 6, 1226; (c) C. Gütz, R. Hovorka, G. Schnakenburg and A. Lützen, Chem. - Eur. J., 2013, 19, 10890.

9 (a) Z. He, W. Jiang and C. A. Schalley, Chem. Soc. Rev., 2015, 44, 779; (b) A. Wu and L. Isaacs, J. Am. Chem. Soc., 2003, 125, 4831.

10 (a) W. Makiguchi, J. Tanabe, H. Yamada, H. Iida, D. Taura, N. Ousaka and E. Yashima, Nat. Commun., 2015, 6, 1; (b) M. Petryk, K. Biniek, A. Janiak and M. Kwit, CrystEngComm, 2016, 18, 4996.

11 (a) A. Schmidt, A. Casini and F. E. Kühn, Coord. Chem. Rev., 2014, 275, 19; (b) D. A. McMorran and P. J. Steel, Angew. Chem., Int. Ed., 1998, 37, 3295; (c) J. E. M. Lewis, A. Tarzia, A. J. P. White and K. E. Jelfs, Chem. Sci., 2020, 11, 677.

12 (a) G. H. Clever and P. Punt, Acc. Chem. Res., 2017, 50, 2233; (b) R. J. Li, J. J. Holstein, W. G. Hiller, J. Andreasson and G. H. Clever, J. Am. Chem. Soc., 2019, 141, 2097.

13 (a) Y. Imai, Y. Nakano, T. Kawai and J. Yuasa, Angew. Chem., Int. Ed., 2018, 57, 8973; (b) Y. Imai and J. Yuasa, Chem. Sci., 2019, 10, 4236; (c) Y. Imai and J. Yuasa, Chem. Commun., 2019, 55, 4095; (d) D. Ogata and J. Yuasa, Angew. Chem., Int. Ed., 2019, 58, 18424.

14 S. P. Morcillo, D. Miguel, L. Álvarez de Cienfuegos, J. Justicia, S. Abbate, E. Castiglioni, C. Bour, M. Ribagorda, D. J. Cárdenas, J. M. Paredes, L. Crovetto, D. Choquesillo-Lazarte, A. J. Mota, M. C. Carreño, G. Longhi and J. M. Cuerva, Chem. Sci., 2016, 7, 5663.

15 R. Berardozzi, E. Badetti, N. A. Carmo dos Santos, K. Wurst, G. Licini, G. Pescitelli, C. Zonta and L. Di Bari, Chem. Commun., 2016, 52, 8428.

16 The two peaks around $3.2 \mathrm{ppm}$ have an underlying broad lump, which indicates the coexistence of other minor species. 